\title{
MENGHITUNG BUNGA KUR DAN NILAI KESETIMBANGAN HUTANG MENGGUNAKAN APLIKASI GEOGEBRA
}

\author{
Saiful Ghozi \\ Program Studi Perbankan dan Keuangan, Politeknik Negeri Balikpapan \\ Jl. Soekarno Hatta Km 08 Balikpapan \\ saiful.ghozi@poltekba.ac.id
}

\begin{abstract}
ABSTRAK
Dalam artikel ini akan dibahas penggunaan aplikasi Geogebra dalam persoalan matematika keuangan. Persoalan pertama adalah menentukan nilai bunga anuitas dari sebuah tabel yang dikeluarkan oleh lembaga jasa keuangan bank. Persoalan kedua adalah menentukan nilai kesetimbangan antara utang dengan bunga majemuk dan tabungan anuitas dengan bunga dan tenor yang sama. Melalui applet yang dibuat dengan aplikasi Geogebra, didapatkan penyelesaian dari persoalan diatas. Penggunaan Geogebra menghasilkan beberapa pendekatan dalam penyelesaian persoalan, yaitu secara aljabar dan geometri. Seain itu fasilitas slider pada Geogebra bermanfaat dalam eksplorasi perubahan nilai parameter.
\end{abstract}

Kata kunci : geogebra, keseimbangan hutang, anuitas, bunga.

\begin{abstract}
This paper discuses utilization of Geogebra in financial problem. The first problem is determining annuity rate base on KPR table which is published by bank of BRI. The second is determining the balance owing and paid on the same tenor. Through the applet had been made by Geogebra, the problems above was solved. The utilization of Geogebra results several approach in solving financial problem, i.e., algebra and geometry. Moreover, slider tool on Geogebra is useful for exploration of parameter differentiation. Keyword: Geogebra, owing balance, annuity, rate.
\end{abstract}

Keywords: geogebra, owing balance, annuity, rate.

\section{Pendahuluan}

Hasil penelitian Cole dkk (2009) di Indonesia dan India menyatakan bahwa literasi keuangan adalah prediktor permintaan jasa keuangan. Sehingga dengan tingkat literasi keuangan yang rendah akan mengakibatkan jumlah masyarakat yang memanfaatkan produk atau jasa keuangan di Indonesia juga rendah (Hidayat,2015). Padahal salahsatu media pemerintah dalam memfasilitasi kegiatan perekonomian masyarakat adalah melalui layanan bank. Untuk itu diperlukan peningkatan literasi keuangan masyarakat indoensia agar aktifitas pemanfataan produk atau jasa keuangan di Indonesia meningkat.

Di Indonesia, matematika keuangan adalah salahsatu topik matematika yang sudah mulai diajarkan di level sekolah dan masuk dalam sebaran matematika peminatan pada 
kurikulum 2013. Dan di level perguruan tinggi khususnya di Politeknik Negeri Balikpapan, pembelajaran matematika keuangan menjadi kendala bagi mahasiswa program studi Keuangan dan Perbankan yang tidak memiliki dasar matematika yang baik di level sebelumnya. Sehingga cenderung membahas konsep dasar yang mestinya dipelajari di level sekolah menengah. Untuk itu diperlukan visualisasi yang baik dari konsep matematika keuangan sehingga memudahkan mahasiswa dalam mempelajar matematika keuangan.

Pemodelan nilai majemuk (Compound Value) dan nilai yang akan datang (Future Value) dengan Geogebra telah dilakukan, dimana nilai kesetimbangan antara nilai majemuk (Compound Value) dan nilai yang akan datang (Future Value) pada saat $\mathrm{i}=10 \%$ dicapai pada saat $n=216$ (Ghozi, 2017b). Dalam artikel ini akan disajikan best practice dari visualisasi dan penyelesaian persoalan matematika keuangan dengan menggunakan aplikasi opensource Geogebra. Di berbagai literatur aktifitas diatas disebut sebagai Computer-assisted Learning (CAL) (Rosadi,2015).

Geogebra adalah aplikasi yang interaktif dan dinamis untuk geometri, aljabar, dan kalkulus yang diperuntukkan bagi kelas pembelajaran. Geogebra dikembangkan pertama kali oleh Markus Hohenwarter pada tahun 2001. Hingga kini Geogebra telah mengalami perbaikan perbaikan fitur termasuk diantara tampilan grafis dalam statitik. GeoGebra saat ini telah digunakan oleh lebih dari 20 juta guru dan murid diberbagai jenjang. 155 Geoogebra Institut (IGI) telah didirikan diseluruh dunia dan diterjemahkan dalam 62 bahasa. Selain sebagai bagian dari alat bantu dalam Computer-assisted Learning (CAL), Geogebra dapat juga berfungsi sebagai alat pemodelan (Hall and Thomas,2017).

Persoalan 1. Berikut disajikan sebuah tabel angsuran KUR yang dikeluarkan secara resmi oleh bank BRI. Informasi yang dicantumkan menyatakan bahwa suku bunganya $0,412 \%$ flat per bulan. Namun berapa sebenarnya suku bunga anuitasnya, mengingat system yag dipakai bank acuannya adalah suku bunga anuitas,? 


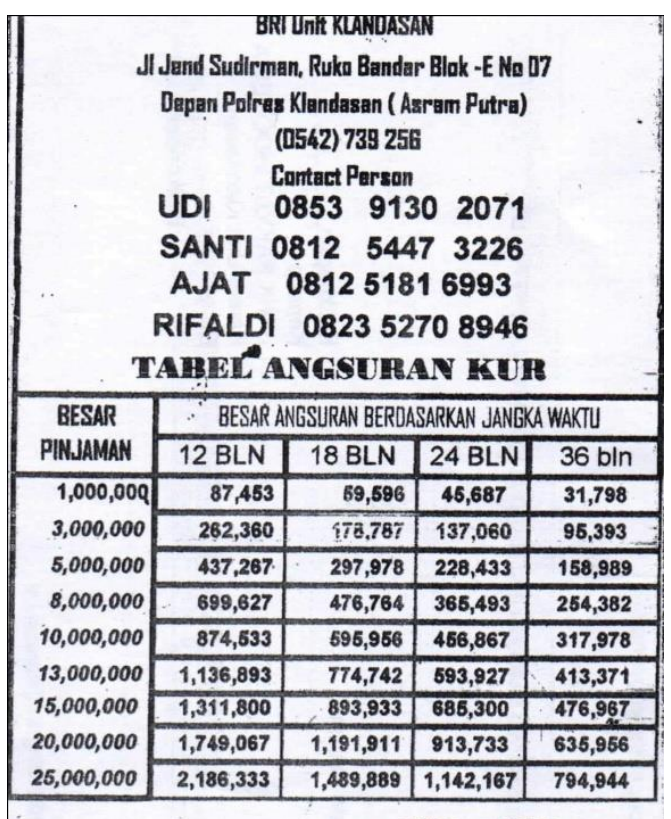

Gambar 1. Tabel KPR KUR BRI

( sumber: Bank BRI Unit Klandasan Balikpapan)

Untuk menentukan suku bunga anuitasnya dari tabel angsuran membutuhkan literasi yang cukup panjang. Fitur dalam Geogebra dapat digunakan untuk menentukan nilai suku bunga anuitas.

Diketahui bahwa persamaan anuitas adalah

$$
P V=\frac{\left(1-(1+i)^{-n}\right)}{i} A
$$

1)

maka dengan manipulasi aljabar diperoleh persamaan polinom berderajad $\mathrm{n}+1$ :

$$
P V(1+i)^{n} i-A(1+i)^{n}+A=
$$

0. ...(Pers. 2)

Dan dengan mengambil salahsatu tenor $\mathrm{n}=12$ dan $\mathrm{PV}=10.000 .000$ pada tabel, didapat persamaan polinom berderajad 13:

$$
\begin{aligned}
& 10.000 .000(1+i)^{12} i- \\
& 874.533(1+i)^{12}+874.533=0 \\
& \text {......(Pers. 3) } \\
& \text { Melalui aplikasi Geogebra didapat }
\end{aligned}
$$
sajian grafik dalam gambar 2 sebagai berikut.

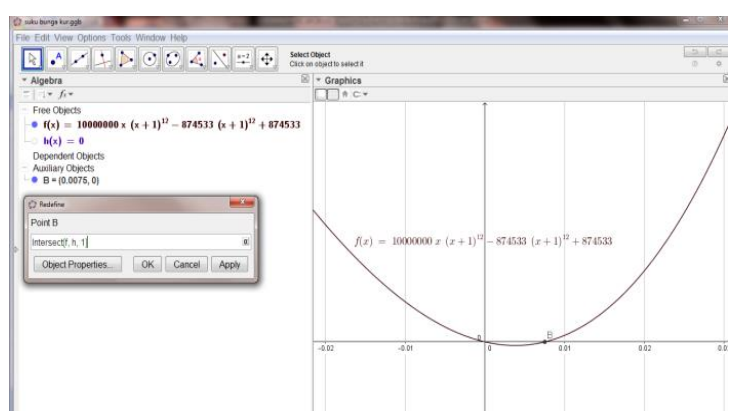

Gambar 2. Tampilan Geogebra : Kurva Persamaan Polinom

Didapatkan salahsatu solusi bernilai positif yang realistis sebagai nilai $i$ pada persamaan polinom diatas adalah $i=0,0075$. Jadi suku bunga anuitas pertahunnya adalah $0,0075 \times 12$ $\mathrm{x} 100 \%=9 \%$.

Selain menggunakan pendekatan solusi persamaan polinom, penentuan bunga anuitas dapat dilakukan dengan pendekatan spreadsheet. Fungsi slider pada aplikasi dapat digunakan untuk menentukan nilai $i$ yang tepat. Pada gambar 3 berikut terlihat bagaimana komposisi angsuran dan utan pada akhir periode angsuran. 


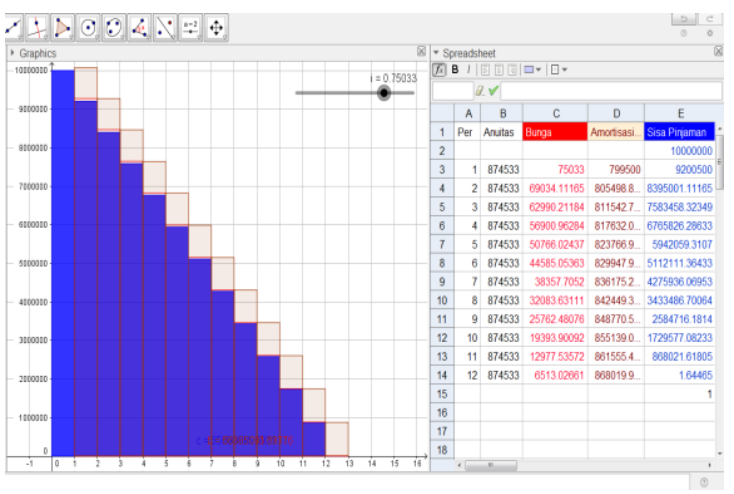

Gambar 3. Applet Histogram Amortiasi

Utang dengan Anuitas (Ghozi, 2016)

Pada applet diatas, untuk angsuran sebesar Rp. 874.533,00 dengan tenor 12 bulan, nilai sisa pinjaman yang mendekati nol dicapai pada saat $i=$ 0,075033. Dengan fasilitas slider eksplorasi nilai $i$ dapat dilakukan untuk menghasilkan sisa pinjaman yang mendekati nol. Selain itu, tampilan histogram dapat memvisualisasikan proporsi nilai sisa pinjaman (biru), nilai bunga (merah) dan amortisasi utangnya (coklat) dari awal hingga akhir cicilan.

Fitur CAS pada Geogebra melengkapi penyelesaian persoalan penentuan suku bunga anuitas diatas dengan pendekatan aljabar. Computer Algebra System (CAS) merupakan salahsatu fitur yang ada pada Geogebra yang memungkinkan untuk melakukan perhitungan matematika dengan cara yang mirip dengan cara-cara manual. Tampilan fitur CAS pada penyelesaian soal datas adalah sebagai berikut.

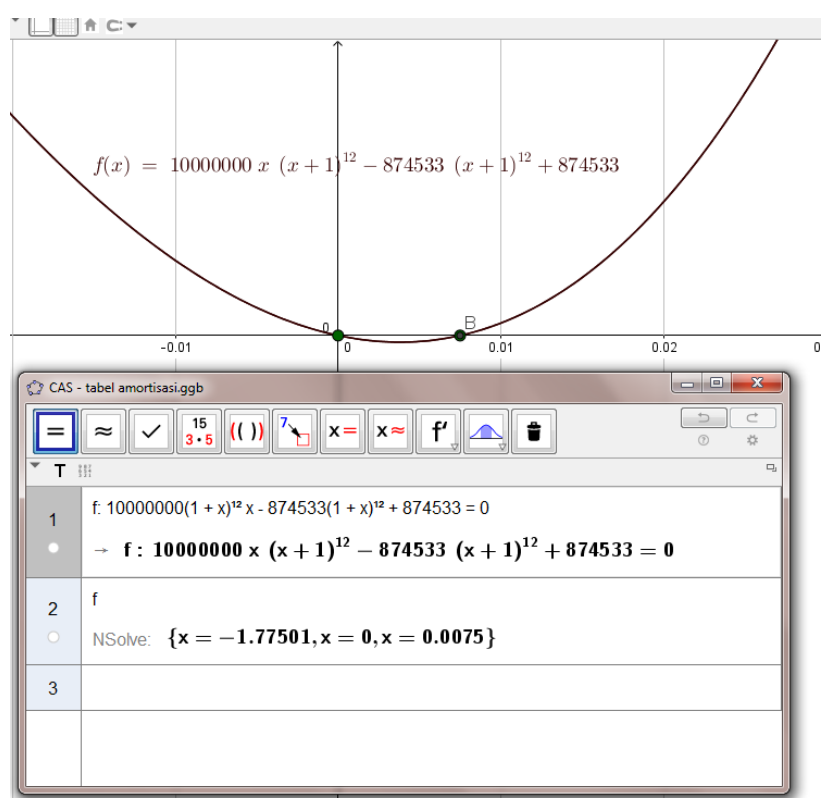

Gambar 4. Fitur CAS dalam Geogebra untuk Menentukan Solusi Persamaan Polinom.

Terlihat bahwa solusi positif dari persamaan polinom 10.000.000(1+ $i)^{12} i-874.533(1+i)^{12}+874.533=$ 0 adalah $i=0,0075$. Jadi dapat disimpulkan besaran bunga efektif dalam satu tahun $=0,0075 \times 12 \times 100 \%=9 \%$.

Jadi geogebra memberikan penyelesaian solusi dari persoalan penentuan bunga anuitas dengan pendekatan geometri dan juga aljabar. Dua pendekatan penyelesaian diatas tidak akan diperoleh jika kita hanya menggunakan aplikasi spreadsheet semisal Microsoft Excel.

Persoalan 2. Tentukan nilai keseimbangan hutang pada tenor 15 tahun antara hutang sebesar Rp400.000 yang dikenai bunga majemuk $10 \%$ p.a, dan tabungan tetap sebesar Rp4.000 
perbulan dengan bunga anuitas sebesar $10 \%$ p.a, dan tentukan kapan hutang akan lunas terbayar.

Misalkan nilai keseimbangan hutang dinyatakan dalam $a$, maka:

$a=S-$

FV ..(Pers.3)

dimana

$\mathrm{S}=$ nilai hutang yang dikenakan bunga majemuk atau disebut nilai majemuk (Compound Value)

$\mathrm{FV}=$ nilai yang akan datang, merupakan akumulasi dari tabungan tetap tiap bulan ( Future Value)

Nilai $\mathrm{S}$ dihitung dengan rumus berikut.

$S=P(1+$

$i)^{n}$ (Pers. 4)

dimana

$\mathrm{P}=$ nilai pokok hutang

$\mathrm{S}=$ nilai majemuk

$\mathrm{i}=$ tingkat bunga per periode bunga

$\mathrm{n}=$ jumlah periode bunga

Sedangkan nilai FV dihitung dengan rumus berikut.

$\mathrm{FV}=\frac{\left((1+\mathrm{i})^{\mathrm{n}}-1\right)}{\mathrm{i}} \mathrm{A} \ldots($ Pers. 5)

dimana

$\mathrm{FV} \quad=$ Nilai yang akan datang

A = Angsuran tetap/ Anuitas

$\mathrm{i}=$ Suku bunga per periode bunga

$\mathrm{n} \quad=$ Jumlah periode bunga
Nilai S (Compound Value) diperoleh dengan subtitusi parameter $i=10 \%, P=400000$ dan $n=15 \times 12=180$ pada Pers. 4

Sehingga didapatkan nilai $\mathrm{S}$ sebagai berikut.

$$
\mathrm{S}=400.000\left(1+\frac{0,1}{12}\right)^{180}=
$$

$1.781 .567,8$

Sedangkan nilai FV (Future Value) diperoleh dengan subtitusi parameter $i=10 \%, A=4000$ dan $n=$ $15 \times 12=180$ pada Pers.5.

Sehingga didapatkan nilai FV sebagai berikut.

$$
\mathrm{FV}=\frac{\left(\left(1+\frac{0,1}{12}\right)^{180}-1\right)}{\frac{0.1}{12}} 4000=
$$

$1.657 .881,4$

Jadi berdasarkan Pers. 3 diatas, nilai $a=1.781 .567,8-1.657 .881,4=$ $123.686,4$

Waktu pelunasan hutang akan dicapai pada saat keseimbangan hutang = 0 , atau dapat ditulis:

$$
\mathrm{S}=\mathrm{FV}
$$

\section{Sehingga}

$$
400.000\left(1+\frac{0,1}{12}\right)^{n}
$$

$\frac{\left(\left(1+\frac{0,1}{12}\right)^{\mathrm{n}}-1\right)}{\frac{0.1}{12}} 4.000$

Dengan serangkaian langkah penyelesaian secara aljabar, akan diperoleh nilai $\mathrm{n}=215,91 \approx 216$ bulan $=$ $216 / 12=18$ tahun. Jadi titik impasnya dicapai pada tahun ke 18 
Dengan Geogebra serangkaian langkah penyelesaian diatas dapat divisualisasikan sehingga menjadi satu kesatuan persoalan yang lebih mudah disimak secara geometri. Applet yang telah dibuat adalah sebagai berikut.

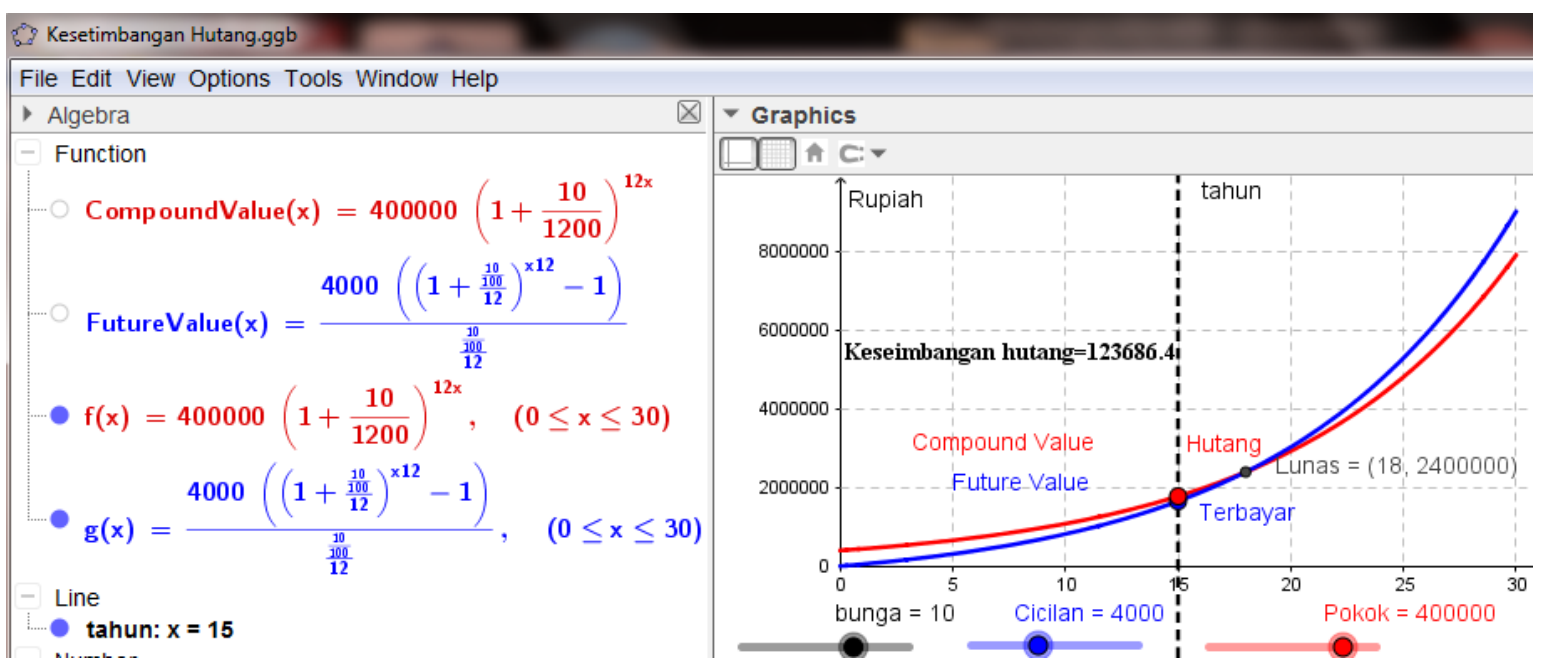

Gambar 5. Applet Kesetimbangan antara Nilai Majemuk (Compound Value) dan Nilai yang Akan Datang (Future Value)(Ghozi, 2017a)

Pada gambar diatas, nilai bunga, cicilan dan pokok hutang majemuk dapat digerakkan menggunakan fasilitas slider. Nilai keseimbangan hutang akan langsung diperoleh pada saat pergerakan nilai parameter $\mathrm{i}, \mathrm{A}, \mathrm{P}$, dan $\mathrm{n}$. Pada persoalan diatas terlihat nilai keseimbangan hutang diperoleh sebesar 123.686,4 dan titik potong antara Nilai majemuk (Compund Value) dan Nilai yang akan datang (Future Value dicapai pada saat nilai $\mathrm{n}=18$, yang artinya hutang majemuk akan lunas pada tahun ke-18.

Dengan pergerakan yang dinamis dari nilai bunga, cicilan anuitas, dan nilai pokok hutang majemuk, eksplorasi lebih luas dapat dilakukan untuk melihat karakteristik pengaruh tiga parameter tersebut terhadap nilai keseimbangan hutang.

\section{Kesimpulan}

Dari pembahasan di atas dapat diperoleh kesimpulan sebagai berikut.

1. Dengan aplikasi Geogebra, nilai bunga anuitas dari tabel KPR KUR BRI diperoleh sebesar $9 \%$ p.a

2. Nilai keseimbangan hutang dapat ditetukan dengan fasilitas slider pada Geogebra melalui eksplorasi nilai parameter yang diketahui.

3. Dengan pergerakan yang dinamis dari nilai bunga, cicilan anuitas, dan nilai pokok hutang majemuk, eksplorasi lebih luas dapat dilakukan untuk 
melihat karakteristik parameter yang mempengaruhi.

\section{Pustaka}

Cole, S. A., \& Shastry, G. K.2008. If you are so smart, why aren't you rich?: The Effects of Education, Financial Literacy and Cognitive Ability on Financial Market Participation. Cambridge, MA: Harvard Business School.

Ghozi, Saiful.2015. Penggunaan Aplikasi GeoGebra dalam Pembelajaran dan Penyelesaian Persoalan Statistik. Prosiding IRWNS $6^{\text {th }}$ Industrial Research Workshop and National Seminar (Bandung, 19 November 2015), pp 15-22.

Ghozi, S. (2016). Tabel Anuitas. Retrieved from https://www.geogebra.org/m/Nw r37XKf

Ghozi, S. (2017a). Kesetimbangan Hutang. Retrieved from https://ggbm.at/qqCGn7zN

Ghozi, S. (2017b). Pemodelan Nilai Keseimbangan Antara Compound Value dan Future
Value Menggunakan Aplikasi Geogebra. Jurnal Sain Terapan, 3(1), 1-5. Retrieved from http://jurnal.poltekba.ac.id/index .php/jst/article/view/195

Hall, Jonas and Lingefjärd, Thomas.2017. Mathematical Modeling: Applications with GeoGebra ${ }^{\mathrm{TM}}$.First

Edition.@John Wiley \& Sons, Inc.

Hašek,Roman, and Petrášková, Vladimíra.2013. GeoGebra in Financial Education. North American GeoGebra Journal (ISSN: 2162-3856) Vol. 2, No. 1, 2013. Tersedia di www.geogebrajournal.com/inde x.php/ggbj/article/download/40/ $\underline{36}$.

Hidajat,Taofik.2015. Literasi Keuangan. Semarang: STIE BANK BPD JATENG

Rosadi,dedi.2015. Computer Assisted Learning Menggunakan Software Open Source R: Past, Present and Future. Makalah Seminar Nasional Matematika Dan Pendidikan Matematika 
